\title{
Comment on "Cultures of Silence and Cultures of Voice: The Role of Whistleblowing in Healthcare Organisations"
}

\section{John Blenkinsopp*, Nicholas Snowden}

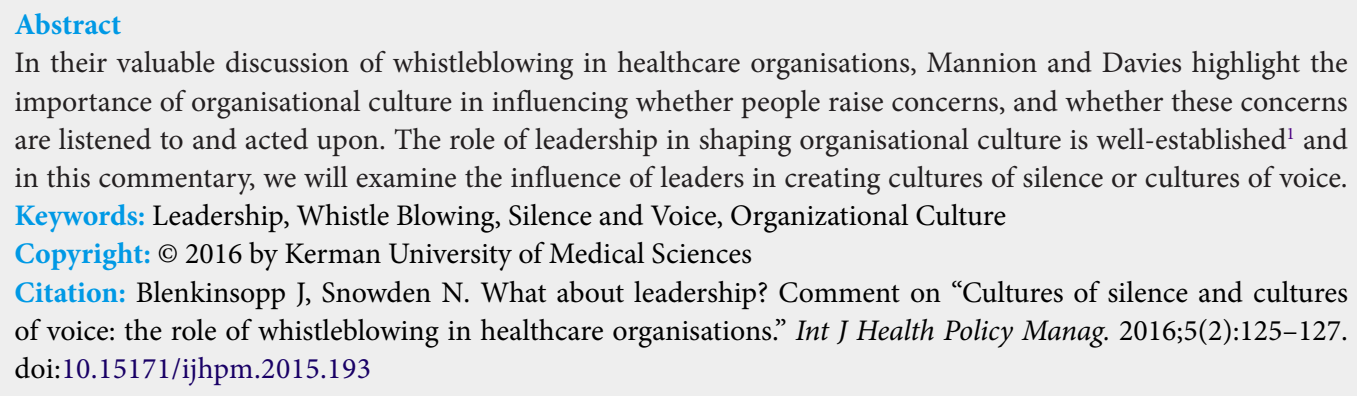
importance of organisational culture in influencing whether people raise concerns, and whether these concerns are listened to and acted upon. The role of leadership in shaping organisational culture is well-established ${ }^{1}$ and in this commentary, we will examine the influence of leaders in creating cultures of silence or cultures of voice. Keywords: Leadership, Whistle Blowing, Silence and Voice, Organizational Culture

Copyright: @ 2016 by Kerman University of Medical Sciences

Citation: Blenkinsopp J, Snowden N. What about leadership? Comment on "Cultures of silence and cultures of voice: the role of whistleblowing in healthcare organisations." Int J Health Policy Manag. 2016;5(2):125-127. doi:10.15171/ijhpm.2015.193

Article History:

Received: 15 September 2015

Accepted: 24 October 2015

ePublished: 25 October 2015

View Video Summary

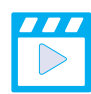

*Correspondence to: John Blenkinsopp

Email: j.blenkinsopp@hull.ac.uk

\section{Introduction}

Whistleblowing is frequently portrayed as the act of courageous individuals 'speaking truth to power', a framing of the phenomenon which assumes efforts to raise concerns will invariably be met by resistance from those in power. And sadly it is indeed the case that many, many whistleblowers have experienced responses from management which are at best hostile and at worst vindictive. ${ }^{2}$ Yet taking managerial antagonism to whistleblowing for granted may prevent us from seeing that such antagonism must be viewed as unacceptable. In the case of healthcare organisations, many senior managers come from a clinical background, and we should find it shocking that (for example) a Medical Director will ignore well-founded concerns over the quality or safety of patient care, perhaps even victimising the individual who raised them. Changing the way healthcare organisations respond to whistleblowing will require significant changes in the attitudes and behaviour of the people who lead them.

\section{The Influence of Leader Behaviours}

The strategic decisions of leaders play an important role in influencing culture, but leader behaviours are also hugely important. If senior management (which includes senior clinicians) are not seen as responding to staff concerns, or worse, are seen to victimise staff who raise concerns, then a culture of silence will reign. Leaders act as role models, their willingness to listen, to be open to criticism, and to admit mistakes sends a very clear message to employees about the kind of behaviours that are expected. Staff considering raising concerns about poor quality care and/or unsafe practice are very aware that the organisational response will be ultimately determined by senior management. Most healthcare organisations have processes in place which allow for concerns to be raised at the highest level. Staff beliefs about the kind of response they might expect will be influenced by culture, but also by their assessment of the character (attitude, values, etc.) of key leadership figures. Clearly staff will be unlikely to raise concerns if they believe these individuals will not act. But they are also less likely to raise concerns in situations where they simply do not know them well enough to judge their likely response. Perhaps it is time for a resurgence in the practice of 'Management By Walking Around.'

Even if potential whistleblowers think management will be receptive, they may be discouraged from speaking up for fear of hostility from their colleagues. ${ }^{3}$ As we discuss below, leaders need to engage in sensegiving to reframe whistleblowing as a positive and valuable act. There is a trend to move away from the whistleblowing terminology to talk instead about 'speaking up' or 'raising concerns.' This change helpfully moves us from viewing whistleblowing as something undertaken only when all else has failed (which indeed most whistleblower protection legislation assumes) to something routine and constructive.

\section{Reframing Whistleblowing}

Although surveys show a significant proportion of healthcare workers have concerns about blowing the whistle, they also indicate that the majority would nevertheless act. How then do we explain the repeated occurrence over decades of healthcare scandals which involve the same basic story of poor quality care becoming endemic in a clinic, department or hospital? In some cases, it is clear concerns were raised and ignored, but in others it appears staff became so accustomed to poor standards they no longer saw a problem about which to raise concerns. Newcomers to the situation may view it differently, but finding that their colleagues appear to have few concerns they may be unsure whether the situation is serious enough to warrant whistleblowing. Given an expectation of hostility to acts of whistleblowing newcomers are motivated to make sense of the situation in ways which privilege inaction over action. ${ }^{4}$ Mannion and Davies ${ }^{5}$ note that assessments of 
whistleblowers are strongly shaped by 'discursive power' 'control over the narrative, managing ambiguity and handling contestation are likely to be central.' Leaders do not have full control of these factors, but their powerful positions certainly allow them to influence the process, engaging in sensegiving to fashion a vocabulary and framework capable of facilitating a deeper understanding of what whistleblowing is for, and when and how it should happen. Leaders can and should create a narrative of whistleblowing as something that it is valued and valuable. One reviewer suggested Virginia Mason Hospital's identification of patients as the ultimate stakeholder was an example, as it would allow leaders to frame speaking up as being for the patient's benefit, rather than the organisation's, thus making it more likely that staff would view raising concerns as legitimate and important.

Never Mind the Motive, Are Their Concerns Valid?

We agree with Mannion and Davies that 'binary distinctions (such as hero/villain; loyal/disloyal; warranted/ unwarranted)... disguise the complexity and ambiguity of whistleblowers and whistleblowing.' Whistleblowers may have mixed motives, indeed in rare cases may act entirely out of malice. Concerns about whistleblowers' motivations often lead leaders to be reluctant to take their concerns seriously. We might draw an analogy with the struggles of campaigners attempting to persuade the justice system to review a conviction or re-open a cold case. Often their challenge is not a lack of evidence, but the reluctance of those in authority to examine that evidence, especially if they view the campaigners as biased or lacking in credibility. Yet in an era of evidencebased medicine, clinical audit and big data it should be much easier to investigate whether a whistleblower's claims have substance, and doubts over a whistleblower's motivation ought not to preclude leaders from taking the allegations seriously, without prejudice to the individuals, teams or units involved.

\section{Leaders Secure Enough to Hear, Listen and Act}

A range of policies and procedures have been developed aimed at making staff feel more secure in raising concerns, but leaders also need to feel secure enough to be open to information which suggests potential problems within the organisation. A key aspect of this security must be a willingness to admit to limitations in one's knowledge. In his criticism of the leaders of Athens Socrates distinguished between ignorance and what he termed 'reproachable ignorance', when a leader is aware of his or her ignorance but refuses to attempt to remedy it. ${ }^{6}$ Whistleblowing confronts a leader with his or her ignorance in a particularly challenging manner. Weinstein suggested managers often react badly to whistleblowing because they view themselves as 'rational agents of rational institutions." Staff raising concerns are effectively suggesting the organisation is behaving improperly, which is threatening to its identity and to the self-identity of its leaders. Developing a suitably reflexive perspective in leaders might be achieved through the use of a mentor or trusted guide, who would act as a sounding board for the leader, and a discrete and respected communication channel for those with concerns about the organisation that they fear to raise.

Even when a leader is prepared to listen, concerns about the security of their position might make them reluctant to act. When we consider major scandals in the delivery of healthcare, we invariably find that senior management could have acted earlier to address the problems, in some case years earlier. A Chief Executive taking action to resolve a problem in response to concerns raised by staff should be praised for this positive response, yet those leaders who act as soon as they become aware of the problem know that acting draws attention to it and risks them being unfairly castigated (by politicians, ${ }^{8}$ the media, etc) for failing to identify and resolve the problem sooner. The scrutiny of healthcare is arguably far greater than any other sector, and is curiously intolerant of mistakes, whereas other industries which have to manage high levels of routine risk (eg, aviation) appear to deal with public and regulatory scrutiny which is more realistic (and less emotive). If a senior manager can expect to be criticised for failings which occurred on his or her 'watch,' even if s/he was unaware of it, then it is understandable if suppression of criticism and denial of the problem is viewed as preferable. Kerr's analysis of what gets actually rewarded in organisations is instructive here ${ }^{9}$ a cynical analysis would suggest the climate currently rewards leaders who ignore problems and suppress the facts, so long as they move on before the size of the problem becomes too great to cover up. We suggest that politicians need to play a leadership role in publically supporting leaders who are willing to respond to concerns and work to improve matters, and in doing so, help to develop a culture which recognises the importance of problem identification and resolution, rather than one which implicitly encourages suppression and denial.

\section{Concluding Remarks}

The notion that problems with quality and safety in healthcare arise predominantly from organisational and systemic issues is a relatively recent way of thinking. ${ }^{10,11}$ Such approaches would view whistleblowing as form of feedback which provides information to improve the system. The fact that many whistleblowers continue to experience considerable hostility suggests many healthcare leaders and professionals still view whistleblowing through the lens of earlier approaches to quality and safety, where errors were viewed as a product of individual mistakes, making whistleblowing by extension a criticism of individuals. Pratt observes that historically medicine was 'simple, largely ineffective, and mostly safe,' whereas as modern medicine is 'complex, highly effective, but dangerous.'12 This observation, while relatively uncontroversial to clinicians, would arguably still shock the general public, and whistleblowing similarly draws attention to problems which shock the public but which are understandable (though not excusable) to those within the system. We suggest there is a need for leaders to think differently about the organisations which they are leading, and to engage with policy-makers and the public in reframing the nature of healthcare.

Ethical issues

Not applicable.

Competing interests

Authors declare that they have no competing interests. 
Authors' contributions

Both authors contributed equally to the writing of this article.

\section{References}

1. Schein, EH. Organizational Culture and Leadership. 4th ed. San Francisco: John Wiley and Sons; 2010.

2. Alford CF. Whistle-blowers: how much we can learn from them depends on how much we can give up. Am Behav Sci. 1999;43:264-277. doi:10.1177/00027649921955254

3. Park H, Blenkinsopp J, Park M. The influence of an observer's value orientation and personality type on attitudes toward whistleblowing. J Bus Ethics. 2014;120(1):121-129. doi:10.1007/ s10551-013-1908-7

4. Blenkinsopp J, Edwards MS. On not blowing the whistle: quiescent silence as an emotion episode. In: Zerbe WJ, Härtel CE, Ashkanasy NM, eds. Emotions, Ethics, and Decision Making. Bingley, UK: Emerald Group Publishing; 2008:181-206.

5. Mannion R, Davies HT. Cultures of silence and cultures of voice: the role of whistleblowing in healthcare organisations. Int $\mathrm{J} \mathrm{Health}$ PolicyManag. 2015;4(8):503-505. doi:10.15171/ijhpm.2015.120

6. Harter N. Socrates' mission against reproachable ignorance: leaders who refuse to acknowledge their ignorance and instead suppress criticism. In: Muhr SL, Lemmergaard J, eds. Critical Perspectives on Leadership: Emotion, Toxicity, and Dysfunction. Cheltenham, UK: Edward Elgar; 2013.

7. Weinstein D. Bureaucratic Opposition: Challenging Abuses at the Workplace. Oxford: Pergamon Press; 1979.

8. Bevan G, Hood C. Have targets improved performance in the English NHS? BMJ. 2006;332(7538):419. doi:10.1136/ bmj.332.7538.419

9. Kerr S. On the folly of rewarding A, while hoping for B. Acad Manage J. 1975;18(4):769-783.

10. Kohn LT, Corrigan JM, Donaldson MS, eds. To Err Is Human: Building a Safer Health System. Washington, DC: National Academy Press, Institute of Medicine; 1999.

11. Department of Health. An organisation with a memory: report of an expert group on learning from adverse events in the NHS chaired by the Chief Medical Officer. London: The Stationary Office; 2000.

12. Pratt SD. Simulation in Obstetric Anesthesia. Anesth Analg. 2012;114(1):186-190. doi:10.1213/ANE.0b013e3182377bbc 